\title{
Intravenous streptokinase for acute myocardial infarction reduces the occurrence of ventricular late potentials
}

\author{
Eng-Wooi Chew, Patricia Morton, J Gerard Murtagh, Michael E Scott, D Barry O'Keeffe
}

\begin{abstract}
The occurrence of ventricular late potentials in survivors of acute myocardial infarction treated with intravenous streptokinase was compared with that in a conservatively treated group and the relation between ventricular late potentials and patency of the infarct related artery was examined. Of 115 patients admitted with a first infarct, 55 were treated with intravenous streptokinase (streptokinase group) and 60 were treated conservatively (non-streptokinase group). A signal averaged electrocardiogram was recorded in all patients and coronary angiography was performed in $45(81.8 \%)$ of the streptokinase group and in $21(35 \%)$ of the non-streptokinase group. At a $40 \mathrm{~Hz}$ filter setting ventricular late potentials were significantly less common in patients treated with streptokinase $(9(16.4 \%)$ of 55$)$ than in those who were not $(26(43 \cdot 3 \%)$ of 60$)$. A total of 66 patients underwent angiography. Of the 26 who had closed infarctrelated arteries, 17 had ventricular late potentials at a $40 \mathrm{~Hz}$ filter setting (sensitivity $65.4 \%$, specificity $95 \%$ ) and 38 of the 40 patients with a patent infarctrelated artery did not have ventricular late potentials (sensitivity $80.9 \%$, specificity $89.5 \%$ ).
\end{abstract}

Patients with acute myocardial infarction treated with intravenous streptokinase were significantly less likely to have ventricular late potentials than conservatively treated patients and the absence of ventricular late potentials at $40 \mathrm{~Hz}$ filter setting was a good noninvasive predictor that the infarctrelated artery was patent.

Over the past 10 years, several groups using special non-invasive processing techniques have detected low amplitude, high frequency potentials late in the QRS complex and in the ST segment on the surface electrocardiogram. ${ }^{1-3}$ In experimental and clinical studies these correlated well temporally with fractionated electrograms recorded from damaged cardiac tissue. ${ }^{4-6}$ Ventricular late potentials identify patients at risk of ventricular tachycardia after acute myocardial infarction and who are thus at increased risk of sudden cardiac death. ${ }^{7-9}$
Thrombolytic treatment reduces mortality after acute myocardial infarction ${ }^{10-12}$ by limiting infarct size. Because thrombolysis also reduces the risk of ventricular arrhythmias we examined the proposition that ventricular late potentials were less common in patients with acute myocardial infarction who were treated with intravenous streptokinase than in those who were conservatively treated.

Some investigators have suggested that abrupt electrocardiographic repolarisation changes after thrombolytic treatment are predictive of (but with a low sensitivity $(67 \%))$ an open infarct-related artery. ${ }^{13}$ The second object of our study, therefore, was to examine the relation between ventricular late potentials and patency of the infarct-related artery.

\section{Patients and methods}

PATIENTS

A total of 123 consecutive patients admitted to our cardiac unit with a first acute myocardial infarction were enrolled into the study. In all patients the diagnosis of acute myocardial infarction was confirmed clinically, electrocardiographically, and by serum concentrations of total creatine kinase $(\mathrm{CK})$ and creatine kinase MB. Eight patients whose electrocardiogram showed bundle branch block were excluded from the study.

Of the remaining 115 patients, 55 satisfied our criteria for treatment with intravenous streptokinase (the thrombolytic agent used in our cardiac unit), which was given as an intravenous infusion of 1.5 million IU over 20 minutes within six hours of onset of chest pain (streptokinase group). These patients had clear electrocardiographic evidence of evolving myocardial infarction and no contraindication to thrombolytic treatment. All these patients were subsequently managed identically with oral aspirin and intravenous heparin for five days. The rest were treated conservatively (non-streptokinase group). Patients in this group were admitted after the six hour "limit" or had a contraindication to thrombolysis.

\section{SIGNAL AVERAGING TECHNIQUE}

A signal averaged electrocardiogram was recorded at the end of the first week after acute myocardial infarction on a commercial Marquette-15 (Marquette Electronics, Mil- 
waukee) machine that has a high resolution electrocardiogram option. The method is similar to that described by Simson $^{3}$ and Denes et al. ${ }^{8}$ Other investigators have shown that the end of the first week is the best time to perform the recording. ${ }^{714}$ They noted a steady increase in the occurrence of late potentials throughout the hospital stay and that once late potentials had appeared they tended to remain. Late potentials recorded within the first 24 hours may not reflect future risk because the anatomical and electrophysiological alterations of ischaemic myocardium in this phase are unstable.

We used bipolar orthogonal X, Y, Z leads; and signals from 500 beats were amplified, digitised, averaged, and then filtered with bidirectional high band pass filters at $25 \mathrm{~Hz}$ and $40 \mathrm{~Hz}$. We chose to analyse the results at two filter frequencies because there is controversy about which is the best band pass filter frequency for recording ventricular late potentials. Previous work from Denes et al, Verzoni, et al, and Gomes et al suggests that the $40 \mathrm{~Hz}$ filter gives a better compromise between sensitivity and specificity. ${ }^{81516}$

Signals from the three leads were combined into a vector magnitude $\mathrm{V}=\sqrt{\left(\mathrm{x}^{2}+\mathrm{y}^{2}+\mathrm{z}^{2}\right)}$. Automated measurements were provided for the duration of the composite electrogramthat is "filtered QRS duration" (normal < $120 \mathrm{~ms}$ ), the root-mean-square voltage of the last $40 \mathrm{~ms}$ of the filtered QRS complex (normal $>20 \mu \mathrm{V}$ ), and the duration of the terminal low amplitude signals less than $40 \mu \mathrm{V}$ (normal $<38 \mathrm{~ms}$ ). Ventricular late potentials were considered to be present if two or three of the above values were abnormal.

\section{CORONARY ANGIOGRAPHY}

Coronary angiography was performed in 45 $(81.8 \%)$ of the streptokinase group and 21 $\left(35^{\circ}\right)$ of the non-streptokinase group. The decision to carry out coronary angiography was made by the attending cardiologist who was unaware of the results of the signalaveraged electrocardiogram. Often they were patients who had angina or inducible ischaemia on treadmill testing after infarction. The infarct-related artery was identified on the basis of electrocardiographic abnormalities in the acute phase. The degree of residual stenosis was graded according to the criteria of the TIMI (thrombolysis in myocardial infarction) trial investigators. ${ }^{17}$ Vessels in TIMI grades 2 or 3 were classified as "open".

\section{STATISTICAL ANALYSIS}

We used the $\chi^{2}$ test with Yates's correction for dichotomous variables and the two sample $t$ test for continuous variables. We performed regression analysis using the presence or absence of ventricular late potentials as the dependent variable and the characteristics listed in the table as the independent variables. The level of statistical significance was set at 0.05 or 1 in 20 .

\section{Results}

Figure 1 shows the signal averaged electrocardiogram of a patient treated with intravenous streptokinase and fig 2 shows the signal averaged electrocardiogram of a patient treated by conventional means. The table shows the characteristics of patients in the two groups.

When analysed singly, three variables seemed to influence the presence of late potentials. These were the administration of streptokinase, patency of the infarct-related artery, and age. As the table shows, patients treated with intravenous streptokinase for acute myocardial infarction were less likely to have ventricular late potentials at the $40 \mathrm{~Hz}$ filter setting (9 of $55(16.4 \%$ ) in the streptokinase group compared with 26 of $60(43.3 \%)$ in the

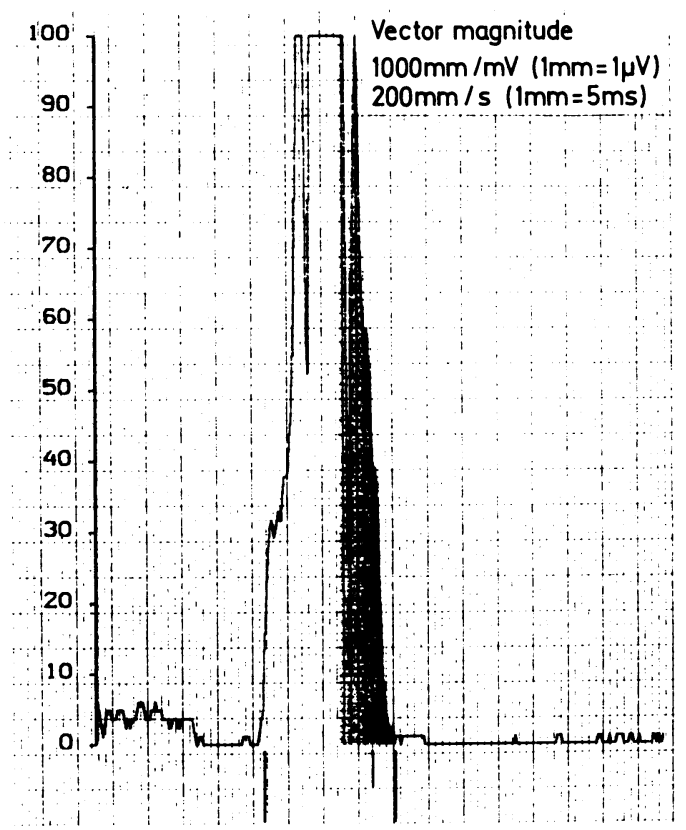

Figure 1 Signal averaged electrocardiogram from a patient with acute myocardial infarction treated with intravenous streptokinase. Shaded area represents last $40 \mathrm{~ms}$ of filtered $Q R S$ complex. Filtered $Q R S$ duration $=92 \mathrm{~ms}$ (normal); root-mean-square voltage of last $40 \mathrm{~ms}=90 \mu \mathrm{V}$ (normal); duration of terminal signals less than $40 \mu \mathrm{V}=16 \mathrm{~ms}$ (normal).

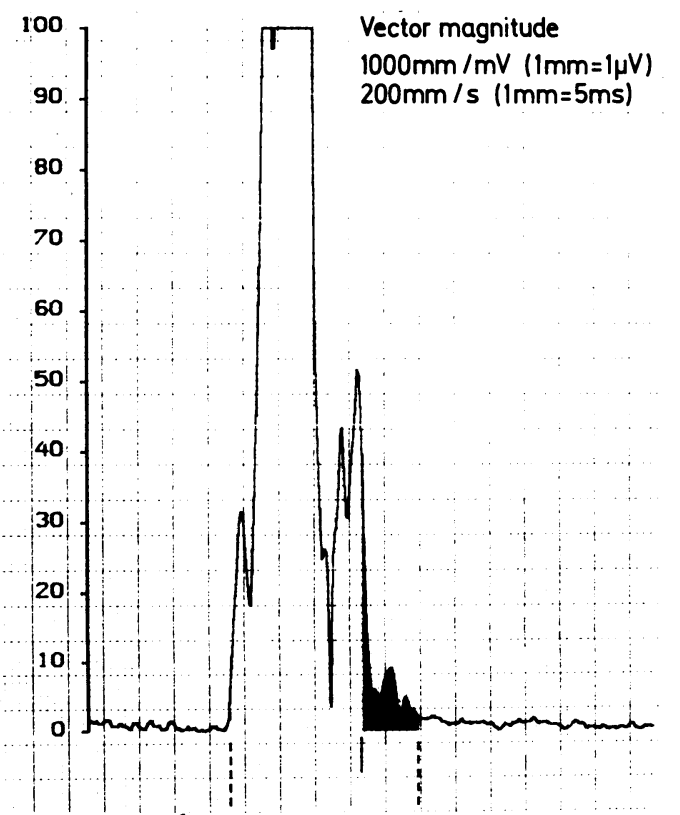

Figure 2 Signal averaged electrocardiogram from a patient with acute myocardial infarction treated conservatively. Shaded area represents last $40 \mathrm{~ms}$ of filtered $Q R S$ complex. Filtered $Q R S$ duration $=132 \mathrm{~ms}$ (abnormal); root-mean-square voltage of last $40 \mathrm{~ms}=$ $13 \mu \mathrm{V}$ (abnormal); duration of terminal signals less than $13 \mu \mathrm{V}$ (abnormal); duration
$40 \mu \mathrm{V}=40 \mathrm{~ms}$ (abnormal). 
Characteristics (mean (SD)) of patients in streptokinase and non-streptokinase groups

\begin{tabular}{|c|c|c|c|}
\hline Variable & $\begin{array}{l}\text { Streptokinase } \\
(n=55)\end{array}$ & $\begin{array}{l}\text { Non-streptokinase } \\
(n=60)\end{array}$ & p value \\
\hline $\begin{array}{l}\text { Age (mean (SD)) } \\
\left.\text { Number of men (" }{ }_{0}\right) \\
\text { Peak CK (U/l) (mean (SD)) } \\
\text { Site of } M I \text { : }\end{array}$ & $\begin{array}{cc}56 \cdot 8 & (12 \cdot 4) \\
46 & \left(84^{\circ}\right) \\
1301 & (1049)\end{array}$ & $\begin{aligned} 61.6 & (10.5) \\
41 & (68 \%) \\
1335 & (806)\end{aligned}$ & $\begin{array}{l}0.048 \\
\text { NS } \\
\text { NS }\end{array}$ \\
\hline $\begin{array}{l}\text { Anterior } \\
\text { Inferior } \\
\text { Others } \\
\text { Number with VLP at: } 40 \mathrm{~Hz} \\
\left.\text { Patent artery (" }{ }_{0}\right)\end{array}$ & $\begin{array}{l}30\left(54 \cdot 5^{\circ} \mathrm{o}\right) \\
\left.22\left(40^{\circ}\right)_{0}\right) \\
3\left(5 \cdot 5^{\circ}\right) \\
9\left(16^{\circ}{ }_{0}\right) \\
2\left(3 \cdot 6^{\circ}\right) \\
32 \text { of } 45\left(71_{0}^{\circ}{ }_{0}\right)\end{array}$ & $\begin{array}{l}39(65 \%) \\
18(30 \%) \\
3 \quad(5 \%) \\
26(43.3 \%) \\
6(10 \%) \\
8 \text { of } 21(38 \%)\end{array}$ & $\begin{array}{l}\text { NS } \\
\text { NS } \\
\text { NS } \\
0 \cdot 003 \\
\text { NS } \\
\text { NS }\end{array}$ \\
\hline
\end{tabular}

CK, creatine kinase; MI, myocardial infarction; VLP, ventricular late potentials.

non-streptokinase group $(\mathrm{p}=0.003))$. The patency of the infarct-related artery also significantly influenced the presence of ventricular late potentials. Of the 26 patients with a closed infarct-related artery, $17(65.4 \%)$ had late potentials compared with two $(5 \%)$ of 40 patients with a patent infarct-related artery $(p<0.0001)$. Patients with ventricular late potentials also tended to be older $(p=0.048)$. The occurrence of ventricular late potentials did not seem to be influenced by the other variables such as sex, peak creatine kinase, and infarct site.

The occurrence of ventricular late potentials at $25 \mathrm{~Hz}$ in the two groups was not significantly different (although there was a trend towards a lower incidence in the streptokinase grouptwo $\left(3 \cdot 6^{\circ}\right)$ of 55 in the streptokinase group compared with six $(10 \%)$ of 60 in the nonstreptokinase group $(p=0.33)$. At $25 \mathrm{~Hz}$ the patency of the infarct-related artery was not significantly associated with the occurrence of ventricular late potentials - three $(11.5 \%)$ of 26 occluded arteries and two (5\%) of 40 open arteries had late potentials $(\mathrm{p}=0.57$ ).

Of 66 patients who underwent angiography, 26 had closed infarct-related arteries. Of these, 17 had ventricular late potentials at $40 \mathrm{~Hz}$ (sensitivity $65.4 \%$, specificity $95 \%$ ) but only three had ventricular late potentials at $25 \mathrm{~Hz}$ (sensitivity $11.5 \%$, specificity $95 \%$ ). In 38 of the 40 patients with a patent infarct-related artery, there were no ventricular late potentials at a $40 \mathrm{~Hz}$ filter setting (sensitivity $80.9 \%$, specificity $89.5 \%$ ). At $25 \mathrm{~Hz}$ the corresponding sensitivity was $62.3 \%$ and the specificity was $60^{\circ}$.

When we used multifactorial analysis to examine the relation between the presence of late potentials and the other variables, the best predictor was the patency of the infarct-related artery followed by the administration of intravenous streptokinase and an inferior site of the infarct. The effect of the patency of the infarctrelated artery was independent of that of streptokinase. The influence of age, apparent initially, became unimportant when these variables were taken into account.

\section{Discussion}

Most clinical studies of ventricular late potentials have examined their ability to identify patients at risk of ventricular arrhythmias after acute myocardial infarction. We showed that ventricular late potentials were less common in patients with acute myocardial infarction treated with intravenous streptokinase than in those treated conservatively. Our study also showed that the absence of ventricular late potentials after acute myocardial infarction is a good, non-invasive predictor of the patency of the infarct-related artery. This may be valuable information because thrombolytic treatment is now widely used and the absence of ventricular late potentials may help to identify those patients who will benefit most from coronary arteriography and perhaps further invasive treatment.

Our study showed that the patency of the infarct-related artery exerts an independent effect on the presence of late potentials. Our data, in accord with those of others, ${ }^{918} 19$ do not suggest that the presence or absence of ventricular late potentials correlate with left ventricular ejection fraction. Successful thrombolytic treatment results in an electrically more stable myocardium ${ }^{20-22}$ and Braunwald has suggested that a patent, bloodfilled, infarct-related artery and vascular bed may provide a scaffolding that limits expansion of the necrotic myocardium. ${ }^{23}$ We further propose that the lower incidence of ventricular late potentials in patients treated with intravenous streptokinase may be related to the reduction in mortality in this group compared with a conservatively treated group.

Gang et al found that the occurrence of ventricular late potentials in acute myocardial infarction was significantly less after successful thrombolytic treatment with tissue plasminogen activator $(5 \%)$ than after conservative treatment $(23 \%) .{ }^{19}$ Of the 157 patients studied by Eldar et al, 65 were treated with thrombolysis (24 with streptokinase and 41 with tissue plasminogen activator). ${ }^{24}$ The frequency of late potentials in this group was $14 \%$, compared with $22.5 \%$ in a conservatively treated group. Our results accord with these findings but we found that a higher percentage of patients in both groups $(16.4 \%$ and $43.3 \%$ respectively) had ventricular late potentials. This may be explained by the different filter frequencies used and different definition of ventricular late potentials. The thrombolytic agent administered may be relevant because initial reports from the TIMI trial (phase 1) suggest that tissue plasminogen activator results in higher patency rates of the infarctrelated artery than streptokinase. ${ }^{17}$ Our figure of $43.3 \%$ for late potentials in the conservatively treated group of patients is similar to that found by other investigators. ${ }^{25} 26$

The problems remain of standardising the technique of surface signal averaging and of defining ventricular late potentials in order to compare results between centres. In most studies, the choice of filter setting has been arbitrary. Gomes et al showed that a $25 \mathrm{~Hz}$ filter setting gave a low sensitivity but the best specificity, whereas a $80 \mathrm{~Hz}$ filter provided best sensitivity but low specificity. ${ }^{16}$ A $40 \mathrm{~Hz}$ filter provides a sensitivity and a specificity intermediate between those at $25 \mathrm{~Hz}$ and $80 \mathrm{~Hz}$. Furthermore, Denes et al showed that the $40 \mathrm{~Hz}$ filter gives better reproducibility of 
measurements. ${ }^{8}$ For these reasons we used the $40 \mathrm{~Hz}$ filter in our analysis. Ventricular late potentials detected at $40 \mathrm{~Hz}$ filter setting were a more sensitive and specific method of predicting the patency of the infarct-related artery than the results at $25 \mathrm{~Hz}$. We think that the $25 \mathrm{~Hz}$ filter underestimates the occurrence of ventricular late potentials. Gang et al used the $25 \mathrm{~Hz}$ filter in their study and found that patients with closed infarct-related arteries had a higher (but not statistically significant) incidence of ventricular late potentials than those with open arteries. ${ }^{19}$ Our study showed that the $40 \mathrm{~Hz}$ filter was better in predicting patency of the infarct-related artery. We are awaiting the results of a long term follow up in these patients, to compare the results with the $25 \mathrm{~Hz}$ filter with those with the $40 \mathrm{~Hz}$ filter. Preliminary results suggest that the $40 \mathrm{~Hz}$ filter may give the result that best predicts long term clinical outcome.

Our results showed a relation between late potentials and inferior infarcts. This was also noted by Kuchar et $a l^{7}$ but not by McGuire et $a l^{14}$ or Gang et al. ${ }^{19}$ The reason for this discrepancy may be related to the size of the study population and different definitions of late potentials used. It may be that because the inferior wall of the heart is one of the later parts to depolarise, low amplitude signals that originate there are more likely to become apparent. $^{27}$

This was not a randomised, placebo controlled study because early reperfusion is known to improve survival after acute myocardial infarction and we thought that a randomised trial would be unethical. Patients in the conventionally treated group presented after the six hour "limit" or had contraindications to treatment with streptokinase. Apart from this difference they are a group (table) that is comparable in age, sex, and site of infarct with the streptokinase group.

From this study, we conclude that intravenous streptokinase administered for acute myocardial infarction and the presence of an open infarct-related artery exert independent effects on the presence of late potentials. The absence of ventricular late potentials after acute myocardial infarction seems to be a good non-invasive predictor of the patency of the infarct-related artery. Detection of ventricular late potentials after thrombolytic treatment therefore is an additional non-invasive, simple means of predicting patency of the infarctrelated artery and may help in selecting which patients require detailed invasive investigations.

We thank Dr G McKenzie for his advice on the statistical analysis of the results.

1 Uther JB, Dennett CJ, Tan A. The detection of delayed activation signals of low amplitude in the vectorcardiograph of patients with recurrent ventricular tachycardia by signal averaging. In: Sandoe E, Julian DG, Bell JW, eds. Management of ventricular tachycardia-role of mexilitine. Amsterdam: Excerpta Medica, 1978:80.

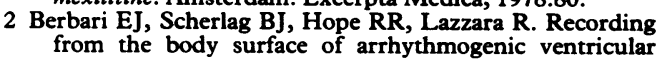

activity during the ST-segment. Am J Cardiol 1978; 41:697-702.

3 Simson MB. Use of signals in the terminal QRS complex to identify patients with ventricular tachycardia after identify patients with ventricular tachycardia
myocardial infarction. Circulation 1981;64:235-42.

4 Simson MB, Untereker WJ, Spielman SR, et al. Relation between late potentials on the body surface and directly recorded fragmented electrograms in patients with ven tricular tachycardia. Am J Cardiol 1983;57:105-12.

5 Gardner PI, Ursell PC, Fenoglio JJ Jr, Wit AL. Electrophysiologic and anatomic basis for fractionated electrograms recorded from healed myocardial infarct. Circulation 1985;72:596-611.

6 Boineau JP, Cox JL. Slow ventricular activation in acute myocardial infarction: a source of re-entrant premature ventricular contraction. Circulation 1973;48:702-13.

7 Kuchar DL, Thorburn CW, Sammel NL. Late potentials detected after myocardial infarction: natural history and prognostic significance. Circulation 1986;74:1280-9.

8 Denes P, Santarelli P, Hauser RG, Uretz EF. Quantitative analysis of the high-frequency components of the terminal portion of the body surface QRS in normal subjects and in patients with ventricular tachycardia. Circulation 1983; 67:1129-38.

9 Verzoni A, Romano J, Pozzoni L, Tarricone D, Sangiorgio S, Croce L. Prognostic significance and evolution of late ventricular potentials in the first year after myocardia infarction: a prospective study. $P A C E$ 1989;12:41-51.

10 Gruppo Italiano per lo Studio della Streptochinasi nell' Infarto Miocardico (GISSI). Effectiveness of intravenous thrombolytic treatment in acute myocardial infarction. Lancet 1986;i:397-402.

11 Yusuf S, Collins R, Peto R. Intravenous and intracoronary fibrinolytic therapy in acute myocardial infarction overview on results on mortality, reinfarction and sideeffects from 33 randomized, controlled trials. Eur Heart $J$ 1985;6:556-85.

12 Simoons ML, Serruys PW, van den Brand M, et al. Improved survival after early thrombolysis in acute myocardial infarction: a randomised trial by the Interuniversity Cardiology Institute in The Netherlands. Lancet 1985;ii:578-82.

13 Richardson SG, Morton P, Murtagh JG, Scott ME O'Keeffe DB. Relation of coronary arterial patency and 'Keeffe DB. Relation of coronary arterial patency and
left ventricular function to electrocardiographic changes left ventricular function to electrocardiographic changes
after streptokinase treatment during acute myocardial after streptokinase treatment during acut
infarction. Am J Cardiol 1988;61:961-5.

14 McGuire M, Kuchar D, Ganis J, Sammel M, Thorburn C. Natural history of late potentials in the first ten days after acute myocardial infarction and relation to early ventricular arrhythmias. Am J Cardiol 1988;61:1187-90.

15 Verzoni A, Romano S, Tarricone D, Sangiorgio S, Croce L Quantitative analysis of the high-frequency components of the signal-averaged QRS complex in normal subjects and in patients with ventricular tachycardia. New Trends in Arrhythmias 1987;3:7-16.

16 Gomes JA, Winters SL, Stewart D, Targonski A, Barreca P. Optimal band pass filters for time domain analysis of the signal-averaged electrocardiogram. Am J Cardiol 1987;60: signal-a

17 Chesebro JH, Knatterud G, Roberts R, et al. Thrombolysis in Myocardial Infarction (TIMI) trial, phase 1: a comparin Myocardial Infarction (TIMI) trial, phase 1: a comparison between intravenous tissue plasminogen activator and intravenous streptokinase. Clinical findings

18 Pollak SJ, Kertes PJ, Bredlau CE, Walter PF. Influence of left ventricular function on signal averaged late potentials in patients with coronary artery disease with and withou ventricular tachycardia. Am Heart J 1985;110:747-52.

19 Gang ES, Lew AS, Hong MA, Wang FZ, Siebert CA, Peter $T$. Decreased incidence of ventricular late potentials after successful thrombolytic therapy for acute myocardial infarction. N Engl J Med 1989;321:712-6.

20 Vermeer F, Simoons ML, Lubsen J. Reduced frequency of ventricular fibrillation after early thrombolysis in myocardial infarction. Lancet 1986;i:1147-8.

21 Kersschot IE, Brugada P, Ramentol M, et al. Effects of early reperfusion in acute myocardial infarction on arrhythmias induced by programmed stimulation: a prospective, raninduced by programmed stimulation: a prospective,

22 Sager P, Perlmutter R, Rosenfeld L, McPherson C, Wackers F, Batsford W. Thrombolysis decreases sudden death and F, Batsford W. Thrombolysis decreases sudden death and arrhythmogenic potential after anterior myocardial infarc-
tion with aneurysm formation [Abstract]. Circulation tion with aneurysm formatio
1987;76(suppl IV):IV-261.

23 Braunwald E. Myocardial reperfusion, limitation of infarct size, reduction of left ventricular dysfunction, and improved survival. Should the paradigm be expanded? Circulation 1989;79:441-4.

24 Eldar M, Leor J, Hod H, Rotstein Z, Truman S, Kaplinsky E, Abboud S. Effect of thrombolysis on the evolution of late potentials within 10 days of infarction. Br Heart $J$ 1990;63:273-6.

25 Gomes JA, Mehra R, Barreca P, El-Sherif N, Hariman R, Holtzman R. Quantitative analysis of the high frequency components of the signal-averaged QRS complex in patients with acute myocardial infarction: a prospective study. Circulation 1985;72:105-11.

26 Breithardt G, Schwarmaier J, Borggrefe M, et al. Prognostic significance of late ventricular potentials after acute myocardial infarction. Eur Heart J 1983;4:487-95.

27 Breithardt G, Borggrefe M. Pathophysiological mechanisms and clinical significance of ventricular late potentials. Eur Heart $J$ 1986;7:364-85. 